\title{
Gender Mainstream Image of Elementary School Teachers in Germany
}

\author{
Petia Genkova \\ University of Applied Sciences, \\ Osnabrueck, Germany
}

\author{
Tobias Talrisch \\ Ernst Reinhardt Munich, \\ Planegg, Germany
}

\begin{abstract}
In the study at hand, the image of an elementary school teacher in public shall be analyzed in detail: his/her reputation, characteristics, and trust in him/her. Especially the image of elementary school teachers shall be considered. This investigation deals with the question "Why men mainly teach at secondary schools". A reason for this could the bad image and the appreciation towards elementary school teachers in society. To counter these tendencies, measures have been taken, like Boy's Days, to make the elementary school more attractive for men, too. With the help of polarity profiles and distance scales, the images of male and female elementary school teachers are compared. The results show that the image of elementary school teachers is overall positively rated, but men working at elementary schools are imputed to show alternative behavior and female characteristics. Further research and implication for acting are necessary to find out what relationships exist between the image and the choice of profession of elementary school teachers to take effective mainstream measures.
\end{abstract}

Keywords: image, elementary school, gender mainstream, polarity profile, stereotype, gender, elementary school teacher

\section{Introduction}

In the study at hand, the image of an elementary school teacher in public shall be analyzed in detail: his/her reputation, perceived characteristics, and trust in him/her. Especially the image of teachers at elementary schools is considered, who lay the foundation for education and introduce our kids to the usual cultural techniques, like reading, writing, and calculating. The investigation shall contribute to the comprehension why men mainly teach at secondary schools and are not interested in functioning at elementary schools. Especially the difference between female and male elementary school teachers is interesting. Regarding gender mainstream, the deployment of men at elementary schools is more and more discussed. Different measures, like Boy's Days, shall make the profession of an elementary school teacher more attractive and popular for men. What is the society thinking of an male elementary school teacher? Is he just an effeminate being because he is working with kids in a so called "women's profession"? Is he afraid of hard work, leisure time-oriented, and lazy? Or is he a necessary and needed compensation for the more and more monotonous "women's society of elementary school"? 


\section{Theoretical Background}

Because the term "image" in everyday's language is used synonymously for the terms of "reputation", "character", "nimbus", "renomme", "regard", "prestige", "appearance", "general orientation", "notion", "prejudice", or "stereotype", a differentiation to these descriptions is difficult with regards to content (Reisch, 2008; Essig, Soulas de Russel, \& Semanakova, 2003). Caused by its extension to everyday's language, a definitional haziness of the "image" term could not be avoided, even in specialist literature. The huge amount of publications has not lead to accuracy, but more to confusion for this term (Salcher, 1995). However, the term "image" is strongly connected to the term "attitude".

Moser (2002) defined image as "subjective notions or internal pictures that users have of a product" (p. 152). They are learned by the course of life through experience which could be either personal, direct experience, or also experience that has been made by other persons and is being adapted (Moser, 2002).

Reisch (2008) furthermore distinguished between self-image and third-person image. Self-image is the "picture" that a person has of himself/herself, or a kind of attitude towards himself/herself. This attitude is divided in notional, actual, and desired self-image. The third-person image is the image that others have of oneself or the attitude of others towards oneself. Thus, the image has, like other attitudes, an affective component and reflects positive and negative associations, whereupon information or perceptions of others can co-affect the overall impression, too. This also counts for the image of an elementary school teacher. Image as an attitude also includes a cognitive and conative component. This definition is considered in the study at hand, too.

Although there are many studies about image that are strongly connected to advertising psychology or political image, there are only a few that deal exclusively with the image of the teacher's profession.

Investigations about the teacher's profession and the according prestige were elaborately conducted in 1976 by Glagow for the first time. These are followed by the scientifical investigations of Gerner (1981) and Barz (1999) (as cited in Reitmajer, 2000). It was the goal of these studies to research the reputation of teachers in society, amongst other things.

A special influence on the further image creation however has investigations conducted and published by polling firms. Many of the findings are only descriptively presented and are rather quantitative. Thus, these rather help to generate hypotheses for further investigations than to test for hypotheses. These investigations are representative, but they do not explicitly provide distinguished analyses about the teacher's profession. The essential results of these analyses are shortly summarized in the following, especially considering the image of teachers.

It becomes obvious that about $78 \%$ of all namings of these investigations include positive ratings, thus, teachers are rather credited with positive characteristics than negative. Here, also the statuses of parents play a role: parents, whose children do not go to school, yet hold back with namings of positive attitudes; parents, whose children already go to school, are in the normal average (Glagow, 1976).

In a research project of the Ludwig-Maximilians-Universität München (University of Munich), the teacher's profession was lastly investigated in 1998-2000, representatively for Bavaria. Reitmajer (1999; 2000) concluded that the high-ranking role model function is increasingly becoming lost. Indeed, teachers are being named on the third position in an unaided request ("What professions have the highest reputation for you?") after physicians (56\% of the namings) and jurists (22\%), but comparing the profession's prestige in relation to other professions, the result is worse: Of 12 professions being subject to an evaluation, the profession of an 
elementary school teacher is located on the eighth position, located on a position before are secondary school teachers. At the same time, teachers of persons with a higher education and until 30 years are significantly more critically regarded (Reitmajer, 2000).

Reitmajer (2000) stated that most of the persons that can image to work as a teacher already have completed an academic career and want to escape from the frustrations of their own profession. The profession of a teacher seems to offer greater free space (and longer free time) than the actual profession of the interviewed persons. The vocational engagement of teachers is overall appreciated by $40 \%$ of the interviewed persons, which is contrasted by $45 \%$ that wish more engagement and motivation. Thereby, the educational background of the interviewed persons is a crucial criterion, because persons holding a certificate of secondary education and persons with professional education state that teachers are sufficiently engaged, whereas persons holding a general qualification for university entrance or having finished studies are not convinced by their performance (Reitmajer, 2000). Older persons overall express more positive statements than younger ones.

The Institute for Public Opinion Polling Allensbach (2008) show similar results by using the Profession Prestige Scale. With the fourth place, elementary school teachers hold an ordinary ranking after physicians, priests, and university professors. Additionally, their reputation increased for 6 points compared with a study from the year 2003, only physicians could achieve an equal increase in appreciation. At least $33 \%$ of the interviewed persons named the teacher at elementary schools for the five most prestigious professions, thus, this profession was connected to appreciation for every third person.

Comparing East and West Germany, a significant difference in the opinion becomes obvious, due to in the West, only $31 \%$ of the interviewed persons appreciate the elementary school teacher, whereas in the East, $39 \%$ do so. Compared with this, the profession of a lecturer is located on the 12th place from overall 17 places and $14 \%$ of the namings in the lower area.

Sequentially regarding the course of the prestige values of teachers of elementary schools since the beginning of the studies, it can be concluded that in the last 20 years, a continuous increase in appreciation existed. In the year 2004, the values rose above the original global maximum value of 37\% from the year 1966 to $40 \%$. Because in the two surveys from 2004 and 2005, not especially the profession of the elementary school teacher, but the profession of the teacher in general was polled, no clear statements can be provided for these two years of investigation about the prestige of an elementary school teacher. The trend however shows that in these two years, the reputation must have been increased.

The Confidence Index is an international study about the trust of citizens in different professions that is yearly conducted by the Society for Consumer Research (GfK). Initiated in 2003, nine different professions were internationally investigated regarding their trust. The GfK investigated in 2008 the trust of overall 19,760 persons in 19 European countries, as well as in the USA for the following 20 professions and organisations for the first time: physicians, bankers, officials, firefighters, trade unions, journalists, church, teachers, managers of big companies, marketing, market researcher, military, politicians, policemen/policewomen, postmen/postwomen, lawyers, judges, environment protection organizations, advertiser, and welfare groups (GfK Group, 2008).

In the international comparison, German teachers are with $83 \%$ trust even above the Western European mean value of $79 \%$. Only teachers in Sweden (89\%), Portugal (88\%), Belgium (88\%), and Spain (86\%) enjoy more trust. The last places are hold by the Greek teachers with only $67 \%$. In Western Europe, the trust in teachers is located on the third place, before are firefighters (94\%) and physicians (84\%). 
In contrast to this, teachers in Central and Eastern Europe are believed to have an especially high credibility, due to pedagogues receive $87 \%$ of trust on average there and are at the top of the Eastern European trust index, significantly before firefighters $(80 \%)$ and physicians $(78 \%)$. For overall Europe, there is a trust index of $82 \%$ and thus the third place for teachers behind firefighters (91\%) and physicians (83\%).

In the worldwide comparison, German teachers are above average trustworthy: When globally seen teachers enjoy only $81 \%$ trust on average, teachers in Germany are with $83 \%, 2 \%$ more trustworthy. The highest reputation have teachers in India (92\%).

In what way does the public image of the male elementary school teachers differ from the one of female elementary school teachers, especially when gender mainstream is inversely thought here?

\section{Methods}

\section{Research Question}

The investigation has the central question to investigate the image of male elementary school teachers in contrast to the one of female elementary school teachers. A reason for the under-representation of men at elementary schools could be the bad image and appreciation towards male elementary school teachers in society. This shall be investigated in this study.

Additionally, gender-specific differences in the perception of female and male elementary school teachers in society shall be shown. For this, it shall be especially tested if male elementary school teachers are differently evaluated regarding their characteristics than their female colleagues. As a reason for this, the fact is to be mentioned that the difference in the perception of male and female teachers has not been considered in previous studies. Because male teachers are a seldom case at elementary schools, but children increasingly grow up without their fathers or male role models, there should be a substantial need for men at elementary schools.

\section{Hypotheses}

It is to be assumed that female teachers are perceived as being more caring, warm, and feeling than male teachers. Male teachers for elementary schools have a worse reputation than their female colleagues and are rated to be less achievement-oriented, competitive shy, and effeminate. This is to be assumed due to commentaries from our pilot studies stating "Male elementary school teachers seem to be more likeable, softer, or more effeminate due to their work with kids" or "Female elementary school teachers are more believed to be able to handle kids affectionately". From these qualitative pre-studies and from literature, the following hypotheses are deviated, which had to be tested with the help of a questionnaire.

Hypothesis 1: Male and female elementary school teachers differ in their public perception regarding their characteristics, whereupon female elementary school teachers are imputed to positive chararcteristics and male elementary school teachers are imputed to negative characteristics.

Beneath the differences between the genders, a differentiation to teachers coming from other kinds of schools shall be made. In comparison to teachers for grammar schools, secondary schools, and secondary modern schools, the extend of reputation of male teachers for elementary school shall be revealed.

Hypothesis 2: The need and the importance of male teachers are regarded as high by the public, independent from gender and education of the participants.

From the first criterion, the circumstance resulted that there had to be two versions of the questionnaire: A version that only asks for the image of the male elementary school teachers, and another version, that only 
refers to female elementary school teachers. Only with this, an independent test for differences is later possible (Brosius, 2004).

Because the image is mainly based on emotional factors, associations and evaluations should be mainly polled. As an adequate measuring method, the polarity profile was chosen. For the polarity profile, oppositional pairs of spontaneous associations of an expert pilot study have been developed and 21 pairs according to the 16PF-R of Schneewind (1998) have been used. The 16 primary dimensions were thereby: heartiness, logical deductive reasoning, emotional stability, dominance, liveliness, consciousness for rules, social competence, emotionalism, vigilance, elevation, privateness, solicitude, openness towards change, self-sufficiency, perfectionism, and strain. The five global dimensions: extraversion, anxietiy, self-control, independency, and rigidity.

The intentional side of the image as an attitude was measured with the help of the Social Distance Scale of Bogardus (1947). The closer the person lets the elementary school teacher, the better is his/her opinion about him/her. For this purpose, the original questions of Bogardus were slightly varied by, e.g., asking the participants, if they could imagine a wedding between a good friend and an elementary school teacher.

For the third criterion, a grade scaling was appropriate that directly puts different professions in a ratio by means of their reputation. The participants were asked to rank the professions. By this, on one hand, the different teaching posts can be analyzed among each other in a primary grade scaling and in a secondary grade scaling, the ratio to other professions. For the first scaling, the teaching posts of elementary school, secondary modern school (from year 5 to 9), secondary school, and grammar school were chosen. The professions of physician, politician, lawyer, journalist, and bookseller were representatively asked to be compared. With the help of this, the reputation could be directly asked.

\section{Sample}

Three hundred and eighteen people from Bavaria took part in the investigation. Among them, 53.1\% $(N=169)$ were female and $46.9 \%(N=149)$ were male. Their age varied between 13 and 78 years and the average age was $30.5(S D=11.1)$. Concerning their marital status, $73.4 \%$ of the participants were unmarried, $22.2 \%$ married, $2.2 \%$ divorced, and $1.6 \%$ widowed. Among the unmarried participants, $56.3 \%$ live in a relationship and $43.7 \%$ have no steady relationship. Of all polled persons, $19.2 \%$ have own kids. More than half of the participants (55.3\%) are working, 38.6\% are being educated (pupils/students/trainees), 3.2\% are unemployed, and $2.5 \%$ are retired. One point six percent $(N=5)$ of the participants are pupils, who have to be separately regarded during the analysis or who have to be excluded. The range of professions reached from farmer, baker, and locksmith to manager and university professor, and $25.2 \%$ are teachers. Of the teachers, $38.8 \%$ are elementary school teachers, $26.2 \%$ are grammar school teachers, $16.2 \%$ are secondary school teachers (classes 5 to 9 ), $7.5 \%$ are secondary modern school teachers, $6.2 \%$ are vocational school teachers, and $5.0 \%$ are teachers for other schools. About half of the participants (49.4\%) graduated from university, $30.2 \%$ hold a degree for university entrance, $13.8 \%$ hold a general certificate of secondary education, $3.1 \%$ hold a certificate of secondary education, and $1.3 \%$ hold other qualifications. Seven participants (2.2.\%) have no qualifications, among them, there are five pupils who are still being educated.

\section{Results and Discussion}

The analysis of the results is structured by the generated hypotheses. Sums of items have been generated 
from the partial areas of the questionnaire and the extreme values of the sums have been checked. By this, the participants could be at least excluded that monotonously stated minimum or maximum values. After the data scrubbing, 315 persons were included to the analysis.

The scales of the polarity profile (5-staged) reaches from 0 to $4(M=2)$, whereupon 0 indicates the firstly mentioned and 4 the secondly mentioned pole. Regarding the statements (7-staged), the scale comprises the area 0 until $6(M=3)$, whereupon 0 stands for "Totally disagree" and 6 for "Totally agree".

\section{Hypothesis 1}

For the analysis of the first hypothesis, teachers were excluded, because they are directly affected and do not reflect the public's opinion. Overall, 235 participants have been considered.

Polarity profile I. To test for this hypothesis, predominantly the polarity profiles and statements were analyzed. After an analysis of mean values, the items of the polarity profile 1 (see Figure 1) related to the profile of the female and male elementary school teachers were recoded, so that the polarities could be structured and graphically better presented and compared.

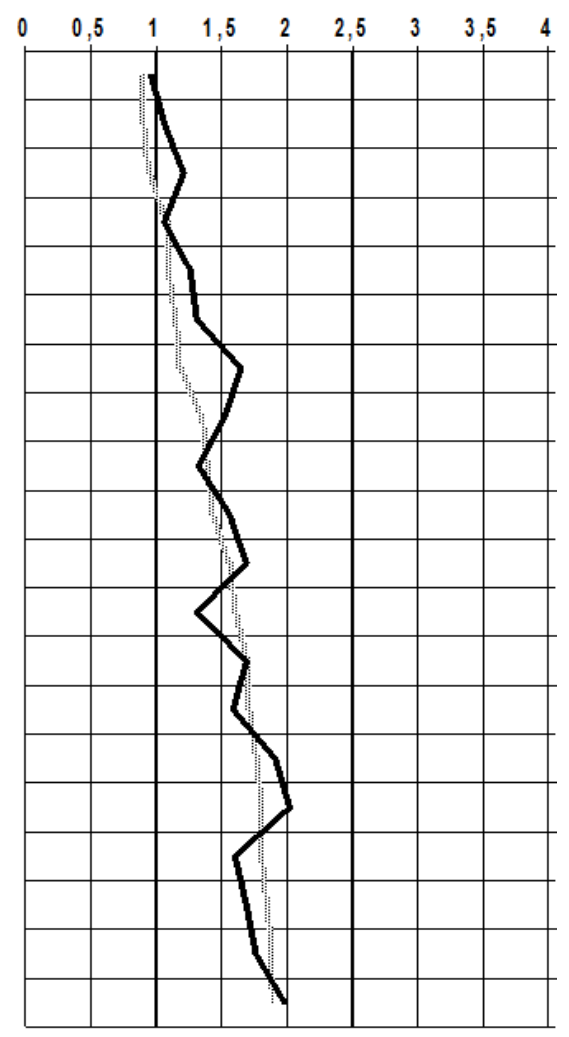

\begin{tabular}{|l|l|}
\hline Likeable/dislikeable & \\
Friendly/unfriendly & \\
Favoured/out-of-favor & \\
Patient/unpatient & \\
Just/unjust & \\
Engaged/easygoing & \\
Diligent/lazy & \\
Self-effacing/arrogant & \\
Balanced/moody & \\
Funny/serious & \\
Team-minded/lone wolf & \\
Easygoing/elegant & \\
Rousing/boring & \\
Idealistic/realistic & \\
Authoritarian/antiauthoritarian \\
Prudent/spontaneous \\
Young/old \\
Athletic/unathletic \\
Modern/old-fashioned \\
Uncool/cool
\end{tabular}

Figure 1. Polarity profile I-Female vs. male elementary school teachers $(N=253)$.

For further testing, $t$-tests for independent samples were conducted for the single items. The independent variable was thereby the gender of the teacher, as dependent variables, the accordant ratings of polarities or statements were used.

Regarding the main hypothesis, significant differences for the items easygoing/elegant, diligent/lazy, and favored/out-of-favor resulted for the image of elementary school teachers. Female elementary school teachers indeed are being rated as slightly easygoing, but male elementary school teachers appear as significantly more 
easygoing $(M=1.31 ; t=2.260 ; d f 3 ; 233 ; p=0.010)$. Male elementary school teachers in return do not seem to be as favored as female ones. Although both genders are basically believed to be rather favored $(M=1.06)$, women $(M=0.94)$ are perceived to be more favored in the profession of an elementary school teacher than men $(M=1.21 ; t=-2.501 ; d f 3 ; 233 ; p=0.015)$. An especial strong difference $(t=-4.066 ; d f 3 ; 250 ; p=0.000)$ is stated by the public regarding diligence, due to male elementary school teachers are with $M=1.65$ in fact on the diligent side, but significantly more lazy than female elementary school teachers $(M=1.18)$.

For the remaining items of the polarity profile 1, there are no further significant differences. It becomes obvious for this investigation by trend that men towards women seem to be slightly less likeable, friendly, just, engaged, self-effacing, funny, team-minded, authoritarian, and prudent. Instead, they appear to be slightly more patient, balanced, rousing, idealistic, younger, athletic, modern, and cooler. These minimal tendencies are only valid for the study and sample at hand and cannot be generalized due to their insignificant differences. However, it is surprising in this case that male teachers for elementary schools in contrast to their female colleagues are perceived as more patient and not that authoritarian.

Polarity profile II. For the second polarity profile (see Figure 2), $t$-tests for independent samples have been conducted, too. The values have however not been recoded, due to the pole result from the 16 Personality Factor Questionnaire (16PF-R). The first five opposite pairs indicate the five global dimensions, followed by 16 adjective pairs that picture 16 personality traits.
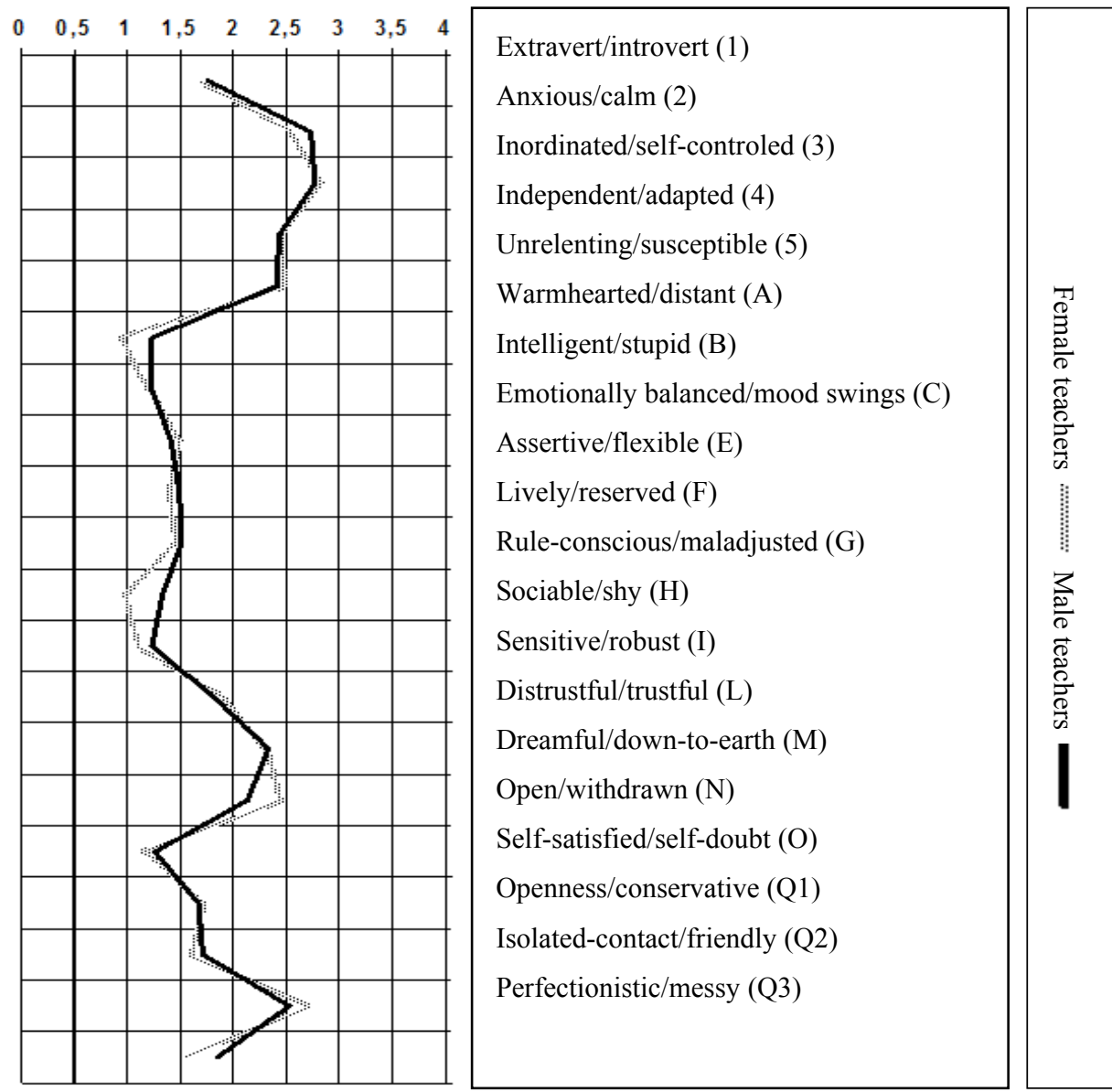

Figure 2. Polarity profile II-Male vs. female elementary school teachers $(N=253)$. 
Differences between male and female elementary school teachers result from the adjective pairs warmhearted/distanced, rule-conscious/maladjusted, dreamful/down-to-earth, and perfectionistic/messy. Female elementary school teachers $(M=0.93)$ are believed to be significantly more warmhearted than their colleagues $(M=1.23 ; t=-2.902 ; d f 3 ; 233 ; p=0.005)$. Furthermore, they count as clearly more conscious of rules $(M=0.97 ; t=-3.733 ; d f 3 ; 233 ; p=0.000)$ than men $(M=1.33)$. Elementary school teachers are rather down-to-earth $(M=2.30)$, however, male elementary school teachers $(M=2.13)$ seem to be not as down-to-earth for the public as their female colleagues $(M=2.45 ; t=2.559 ; d f 3 ; 233 ; p=0.011)$. Women are seen as more perfectionistic at elementary schools, while men $(M=1.85)$ only have a slightly disposedness to perfection, women are imputed to show more closeness $(M=1.57 ; t=4.181 ; d f 3 ; 233 ; p=0.004)$.

Hypothesis 1 is confirmed for the opposing pairs favored/out-of-favor, diligent/lazy, and easygoing/elegant from the first polarity profile. Male elementary school teachers are regarded as being more out-of-favor, lazy, and easygoing than female. In the polarity profile II, the hypothesis is confirmed for the characteristic pairs warmhearded/distanced, rule-conscious/maladjusted, dreamful/down-to-earth, and perfectionistic/messy. Male elementary school teachers are in contrast to female ones perceived as being less warmhearded, rule-conscious, and perfectionistic. Moreover, one thinks that they are less down-to-earth.

The profession of an elementary school teacher is indeed a female's profession, due to women, according to the opinion, can easier deal with children than men. The hypothesis is affirmed here, too. Female elementary school teachers have the image to live healthier than male ones and to try to suit everybody. Male elementary school teachers are given more credit to live an alternative lifestyle, have no ambition and no higher vocational goals, that they are naïve people, because they live in a "gummy bear's world" and furthermore are more childish and playful than their female colleagues.

\section{Hypothesis 2}

With the questionnaire, the participants received - according to its version - a different question by question 10. Persons having been asked for the image of the male elementary school teacher received the question "What do you think, are there too many female teachers at elementary schools?". The participants who should indicate the image of a female elementary school teacher received the question "What do you think, is there an insufficient amount of male teachers at elementary schools?". Hence, there was a concrete relation to the other teacher's gender.

For these two questions, no significant differences regarding the rating exist, so that the results from the two questionnaires do not significantly differ. Thus, for both questionnaires, a common statement is possible. For the hypothesis that there is a lack of men at elementary schools, the results show $64.3 \%$ for its affirmation, $22.6 \%$ reject it, and $13.2 \%$ perceive this ratio as being accurate.

For the evaluation of this question, there is a difference between male and female participants $\left(\chi^{2}(2)=\right.$ $15.41 ; p=0.001$ ). Especially men support this hypothesis with only $52.5 \%$ and reject it by $3.3 \%$ (accurately: $17.2 \%$ ). Regarding women, the affirmation lies at $77.0 \%$, and the rejection only at $14.2 \%$ (accurately: $8.8 \%$ ). Men thus see a less necessity for employing more male teachers at elementary schools.

Regarding the evaluations of the male and female participants separately by meanings of the questionnaire versions, it becomes obvious that this effect only counts for version A, while the hypothesis from version B "too many female teachers" was not significant differently evaluated by women and men. There is a main difference regarding the hypothesis "insufficient amount of male teachers" $\left(\chi^{2}(2)=18.84 ; p=0.001\right)$; women 
reject this hypotheses by only $4.6 \%$ and affirm it with $87.4 \%$, while men reject this hypothesis with $26.3 \%$ and only $59.2 \%$ affirm it.

As it had to be assumed, there is a significant difference between teachers and non-teachers $\left(\chi^{2}(2)=15.73\right.$; $p=0.000 ; N=315$ ). Most teachers (87.5\%) (non-teachers: $64.3 \%$ ) have the opinion that more men should teach at elementary schools, only $6.2 \%$ of the teachers have the contrary opinion or think that the actual situation is accurate, respectively.

Regarding the Social Distance Scale (Bogradus, 1947), there are no significant differences between male and female participants, academicians and non-academicians, and male and female elementary school teachers. The majority of the participants (75.7\%) affirmed to the statement that they would marry an elementary school teacher and $19.1 \%$ at least would agree to a marriage with a brother/sister or other family member. Overall, the acceptance of elementary school teachers is indeed great. However, no further significant results could be investigated.

Hypothesis 2 is marginally confirmed. Women in fact agree upon a higher rate of men at elementary schools with $77.0 \%$, for men there is only a marginal majority of $52.5 \%$. Overall, the hypothesis is confirmed by $64.3 \%$, which is barely satisfying.

The results of the hypotheses testing reveal a negative image for the male elementary school teachers compared to their female colleagues. In most cases, there are negative results for the male elementary school teachers. They seem to have a significant worse image in society than their female colleagues. When directly questioning, the hypothesis "Male elementary school teachers are effete and no real men" is rejected, but a different picture results from the statements and polarity profiles: They are alternative hedgers who have only come to the elementary school, to have much free time and comfortable job without performance control.

The assumption of an alternative lifestyle of male elementary school teachers could also result from the fact that it is still—or even now-extraordinary to work at an elementary school as a man. To have a comparison, the question "progressive lifestyle" could be included in the questionnaire. By this statement, the tendency of this statement would become better explainable. Due to also the quotations have been subject to the investigation with the help of a direct questioning, it has to be clarified, to what extend the social desirability of the questions plays a role. Due to "oblique" commentaries about teacher indeed exist, but the answers adopt an negatory attitude towards the negative quotations, a projective survey about these statements would have been more helpful. Questions could have been considered in this context like "What would your neighbor think about these quotations?" or the like.

Concerning a few points, e.g., "caring" and "nourishes himself/herself healthy", female elementary school teachers are rated better. This effect can not only be traced back to the differences between male and female teachers, but in general to the distinction between women and men, because a healthy nutrition and a caring handling of children are expected from the societal accepted role of a woman. Due to this reason, men seem to be more easygoing. Many of the investigated effects cannot only be solely traced back to the profession, but also to gender differences.

When regarding the evaluations of the teachers, it is striking that mostly unemployed people have a negative image of elementary school teachers. Caused by their unemployment, these persons are frustrated and have of course a negative attitude towards teachers, because they can be blamed for the bad vocational situation. This overall bad mood is then transferred to elementary school teachers, too. If these evaluations of elementary 
school teachers are only "revenge evaluations" or if they indeed base on reflected thoughts, remains unclear. Furthermore, the bad opinion about teachers of the secondary form could have affected the primary form's teachers. It is not surprising that teachers evaluate teachers for elementary school better than non-teachers. Because they so to speak evaluate "themselves", their opinion about "themselves" is significantly more positive. Pupils and relatives or close friends of teachers could be affected in their opinion, as well.

\section{Conclusion}

Elementary school teachers are missed by nearly two-thirds of the interviewed persons. Regarding this question, there are significant differences between women and men. Because this question is related to the particular gender in the questionnaire's versions, this question was one time positively and one time negatively expressed. This could have released reactance concerning the female participants regarding the question "Are there too many women in elementary schools?". A two-sided question like "Are there too many women in elementary schools?" or "Is there an insufficient amount of women?" or a double request of men and women would have been better.

Because it could have been shown that men are wished at elementary schools by teachers and women, but men are skeptical, it has to be researched for what reasons there are retentions towards a higher quote of men. A reason for this could be that male teachers do not favor the ideal of a good male elementary school teacher.

In this investigation, the image of male elementary school teachers was tested. This refers to the current status and how this status is currently perceived in society. For a comparison, further studies could be based on the results of this current status and try to describe the ideal male elementary school teacher. How should a good male elementary school teacher be? The drafted target state could be analyzed and researched upon its acceptance in society, to develop implications for acting of gender-mainstream, like Boys' Days as an advertising strategy for the profession of the male elementary school teacher.

\section{References}

Bogardus, E. S. (1947). Measurement of personal-group relations. Sociometry, 10(4), 306-311.

Brosius, F. (2004). SPSS 12. Bonn: Mitp-Verlag.

Essig, C., Soulas de Russel, A., \& Semanakova, M. (2003). Das image von produkten, marken und unternehmen (The image of products, brands and enterprises). Sternenfels: Verl. Wissenschaft \& Praxis.

Glagow, H. (1976). Der deutsche Lehrer: Sein Image—Zerrbild oder Spiegelbild? (The German teacher: His image—Distortion or mirror image?). Hamburg: Sample Verlag.

Institute for Public Opinion Polling Allensbach. (2008). Ein portrait (A portrait). Retrieved August 29, 2008, from http://www.ifd-allensbach.de/

Lieber, B. (1995). Personalimage: Explorative studien zum image und zur attraktivität von unternehmen als arbeitgeber (Personnel image: Explorative studies on image and on theattractivenes of companies as employers). München: Hampp.

Moser, K. (2002). Markt-und werbepsychologie (Market and advertising psychology). Göttingen: Hogrefe.

Pohl, B., \& Beekmann, A. (2005a). Deutsche schulen—Gut oder ausreichend? Ergebnisse der repräsentativen Eltern-Befragung durch forsa (German schools-Good or sufficient? Results of the representative parent-survey by forsa). Hamburg: Unveröffentlicht.

Pohl, B., \& Beekmann, A. (2005b). Deutsche schulen-Gut oder ausreichend? Ergebnisse der repräsentativen Lehrer-Befragung durch forsa (German schools - Good or sufficient? Results of the representative parent-survey by forsa). Hamburg: Unveröffentlicht.

Reisch, R. (2008). Persönliche PR für lehrerinnen und lehrer: Wie sie ihr image nachhaltig verbessern können (Personal PR for female and male teachers: How you can effectively improve your image). Wien: G. \& G.. 
Reitmajer, V. (1999). Das lehrer-image: Ein forschungsprojekt der Ludwig-Maximilians-Universität München zum Berufsbild und prestige der Lehrerinnen und Lehrer in Bayern (The teacher's image: A research project of the Ludwig-Maximilians-University München on the job-profile und prestige of female and male teachers in Bavaria). Christ und Bildung, 44(10), 8-9.

Reitmajer, V. (2000). Berufsbild und prestige der lehrerinnen und lehrer in Bayern: Dokumentation und ergebnisse (Job description and prestige of female and male teachers in Bavaria: Documentation and results). Oberding: Reimo.

Salcher, E. F. (1995). Psychologische marktforschung (Psychological market research). Berlin: De Gruyter.

Schneewind, K. A. (1998). 16PF-R: Der 16-persönlichkeits-faktoren-test, revidierte fassung-Deutsche Ausgabe des 16PF fifth edition (16PF-R: The 16-personality-factors-test, Revised version-German edition of the 16PF 5th ed.). Bern: Huber.

Society for Consumer Research (GfK) Group. (2008). About GfK. Retrieved September 11, 2008, from http://www.gfk.com/ group/company/ 